\title{
Avaliação de genótipos de Panicum maximum Jacq. à cárie do sino e à mancha foliar
}

\author{
Évellyn da Cunha Macêdo dos Santos ${ }^{1 *}$, Celso Dornelas Fernandes ${ }^{1}$, Jaqueline Rosemeire Verzignassi ${ }^{1}$, Liana Jank ${ }^{1}$, \\ Guilherme Mallmann ${ }^{1}$ e Carolina de Arruda Queiróz ${ }^{1}$
}

${ }^{1}$ Bolsista CAPES. Embrapa Gado de Corte, Av. Rádio Maia, 830, Zona Rural, CEP 79106-550, Campo Grande, Mato Grosso do Sul, Brasil. *Trabalho extraído da dissertação de mestrado da primeira autora.

Autor para correspondência: Jaqueline Verzignassi (jaqueline.verzignassi@embrapa.br)

Data de chegada: 24/06/2013. Aceito para publicação em: 19/12/2014.

$10.1590 / 0100-5405 / 1900$

\section{RESUMO}

Santos, E.C.M.; Fernandes, C.D.; Verzignassi, J.R.; Jank, L.; Mallmann, G.; Queiróz, C.A. Avaliação de genótipos de Panicum maximum Jacq. à cárie do sino e à mancha foliar. Summa Phytopathologica, v.41, n.1, p.35-41, 2015.

Cultivares de Panicum maximum vêm apresentando danos elevados com doenças, como a cárie do sino e a mancha foliar, causadas por Tilletia ayresii e Bipolaris maydis, respectivamente. Objetivou-se, neste trabalho, avaliar a reação de genótipos desta gramínea forrageira a essas doenças. Os experimentos foram conduzidos na Embrapa Gado de Corte, em Campo Grande (MS), no período de fevereiro a julho de 2012. Avaliaramse, semanalmente, as intensidades das doenças em 26 genótipos de $P$. maximum. Dentre os genótipos avaliados, houve variação de graus de resistência para a cárie do sino e para a mancha foliar. As condições ambientais de temperatura e umidade relativa favoráveis à cárie do sino foram $16^{\circ} \mathrm{C}$ a $27^{\circ} \mathrm{C}$ e $62 \%$ a $88 \%$ e à mancha foliar $22^{\circ} \mathrm{C}$ a $27^{\circ} \mathrm{C}$ e $62 \%$ a $83 \%$. A resistência à cárie do sino mostrou ser caráter herdável e o genótipo PM40 comportou-se como a testemunha suscetível, Tanzânia-1, em relação à mancha foliar. $\mathrm{O}$ manejo de $P$. maximum com corte de uniformização mostrou-se promissor na composição das estratégias de controle para redução da intensidade da mancha foliar.

Palavras-chave adicionais: Tilletia ayressi, Bipolaris maydis, forrageira tropical, resistência genética.

\begin{abstract}
Santos, E.C.M.; Fernandes, C.D.; Verzignassi, J.R.; Jank, L.; Mallmann, G.; Queiróz, C.A. Evaluation of Panicum maximum Jacq. genotypes to bell smut and leaf spot. Summa Phytopathologica, v.41, n.1, p.35-41, 2015.

Panicum maximum cultivars have shown great damage due to diseases, such as bell smut and leaf spot, caused by Tilletia ayresii and Bipolaris maydis, respectively. This study aimed to evaluate the reaction of genotypes of such forage grass to those diseases. The experiments were conducted at Embrapa Beef Cattle, in Campo Grande (MS), from February to July 2012. Disease intensities were weekly evaluated for 26 P. maximum genotypes. Among the evaluated genotypes, there were varied degrees of resistance to bell smut and

leaf spot. Favorable environmental conditions of temperature and relative humidity were $16^{\circ} \mathrm{C}$ to $27^{\circ} \mathrm{C}$ and $62 \%$ to $88 \%$ for bell smut and $22^{\circ} \mathrm{C}$ to $27^{\circ} \mathrm{C}$ and $62 \%$ to $83 \%$ for leaf spot. Resistance to bell smut proved to be a heritable character and genotype PM40 behaved like the susceptible control, cv. Tanzânia-1, in relation to leaf spot. The management of $P$. maximum plants using standardization cut proved to be promising in the composition of control strategies to reduce leaf spot intensity.
\end{abstract}

Additional keywords: Tilletia ayresii, Bipolaris maydis, tropical forage, genetic resistance.

O Brasil se destaca mundialmente como o maior produtor e exportador de carne bovina (17), cuja produção é obtida quase que exclusivamente em sistema extensivo (23). A base da bovinocultura de corte e de leite é fundamentada em 177,7 milhões de hectares de pastagens (13) e cerca de 205 milhões de cabeças, tornando a forragem de fundamental importância para a bovinocultura (7).

A importância das pastagens brasileiras não se limita apenas à alimentação animal. O país se destaca, também, como maior produtor, exportador e consumidor de sementes de forrageiras tropicais (20). Na safra 2011/2012, a área deste insumo foi cerca de 151.770 ha, com produção de 44,4 mil toneladas de sementes, o que representou um faturamento na ordem de $\mathrm{R} \$ 838$ milhões (29).

Apesar da importância das pastagens para o Brasil, estas são consideradas culturas de baixo retorno econômico por unidade de área, devido às particularidades da pecuária de corte, como também, à degradação ocasionada por fatores bióticos e abióticos. Com a expansão das áreas de pastagens cultivadas, várias doenças se tornaram preocupantes, reduzindo a produtividade e qualidade das espécies forrageiras (30). Exemplo disso é a redução na produtividade de genótipos de $P$. maximum, infectados com a doença mancha foliar, causada pelo fungo Bipolaris maydis Shoemaker. Tal doença apresenta incidência em todo Brasil, havendo relatos não somente em P. maximum, mas também em Paspalum atratum Swallen cv. Pojuca (4) e Pennisetum purpureum Schum $(9,10)$, se tornando cada vez mais preocupantes para os produtores nacionais.

Os sintomas de mancha foliar em $P$. maximum se caracterizam por inúmeras lesões nas folhas de tamanhos e formatos variáveis, geralmente em torno de 0,3-1,0 cm. Em ataques severos, as lesões coalescem formando largas áreas escuras e necróticas, afetando toda a parte aérea da planta (25).

Costa et al. (10) relataram que na cultura do milho a sobrevivência de B. maydis ocorre em restos culturais infectados e em grãos. Os 
conídios do patógeno são transportados pelo vento e por respingos de chuva. O desenvolvimento da doença ocorre em condições ótimas de temperaturas entre 25 e $30^{\circ} \mathrm{C}$ e com elevada umidade relativa do ar, no entanto, longos períodos de seca, seguidos de dias ensolarados, são condições desfavoráveis à doença.

Outra doença que causa danos às cultivares de $P$. maximum é a cárie do sino, causada pelo fungo Tilletia ayresii Berkeley, sendo considerada uma das enfermidades mais prejudiciais à produção de sementes dessa espécie, comprometendo a produtividade e a qualidade das sementes de P. maximum (30). O fungo infecta as flores e sementes, deformandoas e impedindo o seu desenvolvimento normal. Com o progresso da doença, as sementes infectadas apresentam-se com volume maior, formando internamente massa de esporos com coloração acinzentada, sinais importantes na diagnose da doença, que se rompem liberando e dispersando pelo vento grande quantidade de esporos (27).

A germinação dos teliósporos em campo se dá quando a semente contaminada é semeada, ou quando sementes sadias são depositadas em solos infestados com o patógeno. Este fato ocorre quando nas mesmas condições climáticas favoráveis para a germinação da semente no campo. Após a penetração do patógeno no hospedeiro o fungo se desenvolve intercelularmente e o micélio acompanha o ponto de crescimento da planta, até a formação das panículas. Somente com a formação dos grãos diferenciados ocorre a produção de esporos, que fornecem os nutrientes necessários para sua formação, quando surgem os sintomas/sinais da doença nas panículas $(1,12)$.

O controle químico para ambas as doenças é de aplicação limitada, por ser inviável economicamente (6), quando as áreas são destinadas somente à alimentação animal. Porém, em áreas de produção de sementes, o controle químico pode se tornar viável. Assim, outras estratégias de controle das doenças devem ser desenvolvidas, sendo estas de fácil utilização e baixo custo para o produtor. Dentre elas, o uso de cultivares resistentes se destaca como a mais promissora para o combate às doenças.

No entanto, outros métodos de controle podem ser utilizados, tais como prevenção da entrada de patógeno em uma área ainda não infestada, escolha de local para o plantio em que as condições climáticas não sejam favoráveis ao patógeno, utilização de sementes sadias e o tratamento de sementes e solo (19).

Apesar da importância das doenças foliares que incidem em $P$. maximum, poucos artigos são encontrados na literatura. Dessa forma, este trabalho teve como objetivo avaliar a resistência de genótipos de $P$. maximum à mancha foliar e à cárie do sino.

\section{MATERIAL E MÉTODOS}

Os trabalhos foram conduzidos na área experimental da Embrapa Gado de Corte, em Campo Grande-MS, no período de fevereiro a julho de 2012. Os dados climáticos referentes ao período dos experimentos se encontram na Figura 1.

As avaliações de genótipos de $P$. maximum em relação às duas doenças citadas anteriormente ocorreram em três experimentos distintos: dois testando materiais genéticos para resistência à cárie do sino e, um terceiro experimento, avaliando a resistência de $P$. maximum à mancha foliar, conduzido sob duas formas de manejo de corte de uniformização.

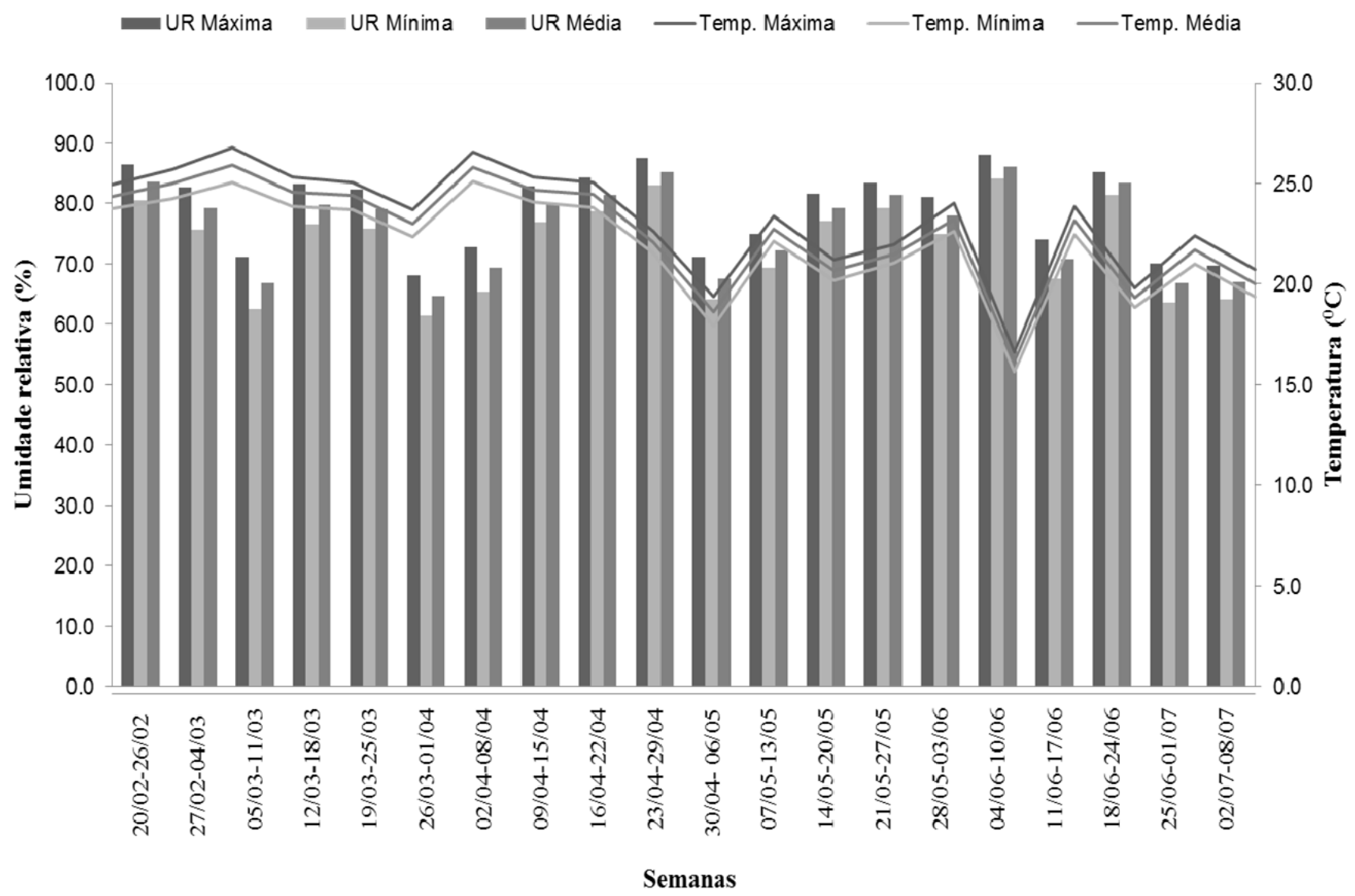

Figura 1. Dados semanais de umidade relativa do ar e temperatura na área experimental da Embrapa Gado de Corte. Campo Grande, 2012. 
Avaliação da resistência de genótipos de Panicum maximum à cárie do sino

Experimento 1

O experimento foi conduzido em blocos casualizados com quatro repetições. As parcelas apresentaram dimensões de 3 metros de largura por 4 metros de comprimento, constituídas por 12 plantas, espaçadas em $1 \mathrm{~m}$ entre linhas e plantas e $3 \mathrm{~m}$ entre blocos.

Foram avaliados 20 genótipos de $P$. maximum: S7, S8, S9, S10, S11, S12, S13, S14, S15, S16, S17, S18, S19, PM32, PM36, PM45, PM46 e as cultivares Tanzânia-1, Mombaça e Massai. O plantio foi efetuado a partir de mudas desenvolvidas em copos plásticos de 500 $\mathrm{mL}$, com substrato de solo e areia lavada na proporção $1: 1$, adubado com a fórmula 10-10-10 (N-P $\left.\mathrm{O}_{5}-\mathrm{K}_{2} \mathrm{O}\right)$, na proporção de $1,25 \mathrm{Kg} / 1000$ $\mathrm{Kg}$ da mistura, em casa de vegetação, onde permaneceram por 30 dias. O transplante das mudas para o campo ocorreu em 10 de janeiro de 2012, fazendo-se adubação das covas com a formulação 10-10-10 $\left(\mathrm{N}-\mathrm{P}_{2} \mathrm{O}_{5}-\mathrm{K}_{2} \mathrm{O}\right.$ ), na proporção de $250 \mathrm{~kg} / \mathrm{ha}$, baseada nos resultados de análise de solo, com vistas à fornecer o mínimo necessário preconizado para a forrageira e saturação em bases em torno de $50 \%$.

As avaliações da doença tiveram início ao final de março de 2012, a partir do início da antese, prolongando-se até dia 6 de julho, quando as plantas das parcelas não apresentavam mais panículas aptas para a coleta. Foram coletadas semanalmente 15 panículas por parcela, as quais foram levadas ao laboratório para avaliação da intensidade da doença (incidência e severidade). A incidência da doença foi avaliada por meio da proporção de panículas com sintomas/sinais de cárie do sino em relação ao número total de panículas. A determinação da severidade da cárie do sino foi realizada por meio da razão do número de ramificações primárias das panículas com sintomas/sinais da doença em relação ao total.

Os dados de intensidade da doença foram transformados para $(\mathrm{x}+0,01)^{1 / 2}$, para se calcular a área abaixo da curva de progresso da doença (AACPD) de cada genótipo, conforme equação proposta por Shaner \& Finney (28):

$$
\mathrm{n}-1
$$

$$
\begin{aligned}
\mathrm{AACPD} & =\sum[(\mathrm{xi}+(\mathrm{xi}+1)) \times 0,5] \times[(\mathrm{ti}+1)-\mathrm{ti}], \\
\mathrm{i} &
\end{aligned}
$$

onde, $\mathrm{n}$ é o número de avaliações, $\mathrm{x}$ é a incidência ou severidade de doença e [(ti+1)-ti] é o intervalo de avaliações consecutivas.

Os valores das AACPD foram submetidos às análises estatísticas utilizando-se o programa Genes - versão 2007.0.0 (11) e as médias foram comparadas pelo teste de Scott-Knott, a 5\% de probabilidade.

\section{Experimento 2}

Com vistas à maior confiabilidade dos resultados, um segundo experimento foi realizado em blocos casualizados com três repetições, dispostos em parcelas constituídas por 10 plantas por linha, com espaçamento de $0,5 \mathrm{~m}$ entre linhas e entre plantas. Nesse novo ensaio, foram avaliadas, novamente, as três cultivares testemunhas (Tanzânia-1, Mombaça e Massai) e os quatro genótipos promissores em fase final de desenvolvimento PM32, PM36, PM45 e PM46, além dos genótipos PM11, PM40 e PM44 de P. maximum.

As mudas foram produzidas da mesma forma que para o experimento 1 e o transplante para o campo ocorreu em 09 de dezembro de 2010, realizando-se adubação das covas com a formulação 5-20-20 (N-P $\mathrm{O}_{5}-\mathrm{K}_{2} \mathrm{O}$ ), na proporção de $250 \mathrm{~kg} / \mathrm{ha}$, baseada nos resultados de análise de solo.

As avaliações de cárie do sino tiveram início em 27 de fevereiro de 2012, concomitantemente às primeiras anteses, e se prolongou até o dia 21 de maio, quando as parcelas não apresentavam panículas para a coleta de amostras. As metodologias de avaliação e análise estatística da doença foram idênticas àquelas utilizadas no experimento 1 .

\section{Experimento 3}

Avaliação de genótipos de Panicum maximum para a resistência de campo à mancha foliar sob duas formas de manejo de corte de uniformização

O delineamento experimental utilizado neste experimento foi em blocos casualizados com três repetições. Cada unidade experimental foi constituída por duas linhas de 7 metros, espaçadas de 2 metros, oriunda de semeadura direta a campo, distribuindo-se $3 \mathrm{~kg}$ de sementes puras viáveis por hectare. $\mathrm{O}$ experimento foi instalado em 06 de janeiro de 2011, em área adubada com a formulação 5-20-20 ( $\left.\mathrm{N}_{2} \mathrm{P}_{2} \mathrm{O}_{5}-\mathrm{K}_{2} \mathrm{O}\right)$, na proporção de $250 \mathrm{~kg} / \mathrm{ha}$. Foram avaliados os seguintes genótipos: PM39, PM40, PM36, PM32, PM11, PM46, PM30 e as cultivares Tanzânia-1, Mombaça e Milênio.

Foram realizadas sete avaliações, com intervalo semanal, da mancha foliar nas parcelas de cada genótipo, sendo metade de cada parcela manejada com corte e a outra parte sem corte. As avaliações iniciaram-se uma semana após o corte, no dia 29 de fevereiro de 2012, quando as plantas começaram a rebrotar.

Para a avaliação da severidade da doença, foram atribuídas notas segundo escala diagramática proposta por Martinez (24) e modificada por Fernandes et al. (15), conforme segue: $0=$ ausência de doença; $1=0$ $0,4 \% ; 2=0,4-1 \% ; 3=1-3 \% ; 4=3-6 \% ; 5=6-13 \% ; 6=13-26 \% ; 7=26-50 \% \mathrm{e}$ $8=>50 \%$ de área foliar lesionada. Os dados de severidade transformados para $(\mathrm{x}+0,01)^{1 / 2}$, sendo posteriormente calculadas as áreas abaixo da curva de progresso da doença das plantas com corte (AACPDc) e sem corte (AACPDs), conforme fórmula proposta por Shaner \& Finney (28):

$$
\mathrm{n}-1
$$

$$
\mathrm{AACPD}=\sum[(\mathrm{xi}+(\mathrm{xi}+1)) \times 0,5] \times[(\mathrm{ti}+1)-\mathrm{ti}],
$$$$
\text { i }
$$

onde, $\mathrm{n}$ é o número de avaliações, $\mathrm{x}$ é a severidade de doença $\mathrm{e}$ [(ti+1)-ti] é o intervalo de avaliações consecutivas.

Os dados foram analisados no programa Genes - versão 2007.0.0 (11) e as médias comparadas pelo teste de Tukey a 5\% de probabilidade.

\section{RESULTADOS E DISCUSSÃO}

\section{Resultados da avaliação de genótipos de Panicum maximum à cárie do sino \\ Experimento 1}

A área abaixo da curva de progresso da severidade da doença (AACPDS) variou de 742,62 a 9,32 e a área abaixo da curva de progresso da incidência da doença (AACPDI) variou de 1370,83 a 198,32 (Tabela 1). Assim, todos os materiais avaliados apresentaram panículas infectadas por T. ayresii, sendo que a cultivar Massai apresentou menor severidade da doença (Tabela 1).

Os genótipos denominados $\mathrm{S}$ são sexuais e, num programa de melhoramento, poderiam ser utilizados no cruzamento com plantas apomíticas, podendo-se gerar plantas superiores quanto à resistência à cárie, como ocorreu, por exemplo, com S10 e S8.

Lima et al. (21), ao avaliarem a reação de híbridos à cárie do sino oriundos dos cruzamentos entre S10 vs. Tanzânia-1, S10 vs. Mombaça e S12 vs. Tanzânia-1, observaram que $60 \%$ dos materiais obtidos foram resistentes à $T$. ayresii, confirmando a possibilidade de que estes genótipos poderiam ser usados como parentais resistentes à cárie do 
sino em programas de melhoramento futuros.

Neste trabalho, porém, não houve genótipos com ausência de sintomas da doença, resultados semelhantes aos trabalhos de Anjos et al. (6) e Delgado et al. (14). Jank et al. (18), ao avaliarem uma coleção de 234 genótipos de $P$. maximum, verificaram que a maioria dos genótipos apresentou sintomas da doença. No entanto, esses autores verificaram que alguns desses genótipos, mesmo em florescimento, não exibiram sintomas, demonstrando grau elevado de resistência.

O mesmo foi observado por Muller et al. (26), ao testarem a resistência de 136 genótipos de $P$. maximum à cárie do sino, encontrando genótipos altamente resistentes à doença, o que evidencia a possibilidade de seleção de materiais como possíveis parentais, visando o desenvolvimento de cultivares resistentes ao patógeno.

Os genótipos S7, S17, S19, PM32, S10 e S8 foram medianamente suscetíveis à doença. Tais resultados corroboram os de Anjos et al. (5) e Anjos et al. (6), que classificaram os genótipos PM32 e Massai como um grupo com menor severidade da doença. No entanto, o mesmo resultado não foi encontrado no trabalho de Fernandes et al. (16), onde o genótipo Massai apresentou alta severidade de cárie do sino. As divergências nas respostas de resistência de campo no binômio de $P$. maximum vs. T. ayresii podem ser atribuídas às condições ambientais distintas durante a realização dos trabalhos.

A cultivar Mombaça e os genótipos S18 e S9 foram alocados no grupo de maior intensidade de cárie, sendo classificados como altamente suscetíveis à doença, o que coincide com os resultados obtidos por Fernandes et al. (16), sobretudo para o genótipo S9.

A estimativa de herdabilidade dos genótipos em relação à cárie do sino foi $77,33 \%$ e $90,76 \%$ para AACPDI e AACPDS, respectivamente (Tabela 1), indicando este caráter como altamente herdável entre os genótipos de $P$. maximum estudados.

No entanto, analisando-se o coeficiente de variação genético, constatou-se 21,21 para AACPDI e 38,22 para AACPDS, indicando baixa variabilidade entre os genótipos estudados para a cárie do sino, assemelhando-se com os resultados de Fernandes et al. (16), que evidenciaram a existência de genótipos com alto grau de resistência à doença, mas com baixa variabilidade para tal.

As altas intensidades da cárie do sino nas plantas variaram segundo o genótipo, ocorrendo no início, na fase intermediária ou no final do período do florescimento (Figura 2). As temperaturas mínimas e
Tabela 1. Intensidade da cárie do sino e parâmetros genéticos de Panicum maximum, expressos pelas áreas abaixo da curva de progresso da incidência (AACPDI) e da severidade (AACPDS). Campo Grande, MS, 2012

\begin{tabular}{ccc}
\hline Genótipo & AACPDS & AACPDI \\
\hline S18 & $742,62 \mathrm{a}^{*}$ & $1289,16 \mathrm{a}$ \\
Mombaça & $571,13 \mathrm{a}$ & $1370,83 \mathrm{a}$ \\
S9 & $563,12 \mathrm{a}$ & $1096,67 \mathrm{a}$ \\
PM45 & $402,71 \mathrm{~b}$ & $956,66 \mathrm{~b}$ \\
Tanzânia-1 & $397,50 \mathrm{~b}$ & $1242,52 \mathrm{a}$ \\
S12 & $380,91 \mathrm{~b}$ & $898,33 \mathrm{~b}$ \\
S14 & $378,35 \mathrm{~b}$ & $1295,00 \mathrm{a}$ \\
PM46 & $368,79 \mathrm{~b}$ & $964,45 \mathrm{a}$ \\
PM36 & $307,01 \mathrm{~b}$ & $892,51 \mathrm{~b}$ \\
S11 & $297,98 \mathrm{~b}$ & $1221,09 \mathrm{a}$ \\
S13 & $296,48 \mathrm{~b}$ & $787,51 \mathrm{~b}$ \\
S15 & $268,31 \mathrm{~b}$ & $1108,33 \mathrm{a}$ \\
S16 & $247,56 \mathrm{~b}$ & $956,64 \mathrm{~b}$ \\
S7 & $215,42 \mathrm{c}$ & $746,68 \mathrm{~b}$ \\
S17 & $163,72 \mathrm{c}$ & $635,83 \mathrm{~b}$ \\
S19 & $151,06 \mathrm{c}$ & $762,23 \mathrm{~b}$ \\
PM32 & $145,06 \mathrm{c}$ & $781,66 \mathrm{~b}$ \\
S10 & $82,59 \mathrm{c}$ & $487,10 \mathrm{c}$ \\
S8 & $80,89 \mathrm{c}$ & $637,79 \mathrm{~b}$ \\
Massai & $9,32 \mathrm{~d}$ & $198,32 \mathrm{c}$ \\
\hline Herdabilidade- médias (\%) & 24,39 & 22,96 \\
\hline Coeficiente de variação genético- médias (\%) & 90,76 \\
\hline & & 38,22 \\
\hline
\end{tabular}

${ }^{1}$ Média de quatro repetições.

*Médias seguidas pelas mesmas letras nas colunas não diferem entre si pelo teste de Scott-Knott a 5\% de probabilidade.

máximas registradas nesses picos foram, respectivamente, $16^{\circ} \mathrm{C}$ e $24^{\circ} \mathrm{C}$ (Figura 1). A umidade relativa do ar variou entre $64 \%$ e $88 \%$, gerando condições favoráveis à doença. Para Tilletia carie (DC.) Tul., em trigo, Cruz Filho \& Chaves (12) verificaram que as condições ideais para germinação de esporos do fungo são temperaturas entre 18 e $20^{\circ} \mathrm{C}$ e alta umidade do solo, bem semelhantes àquelas observadas para $T$. ayresii nesta pesquisa.

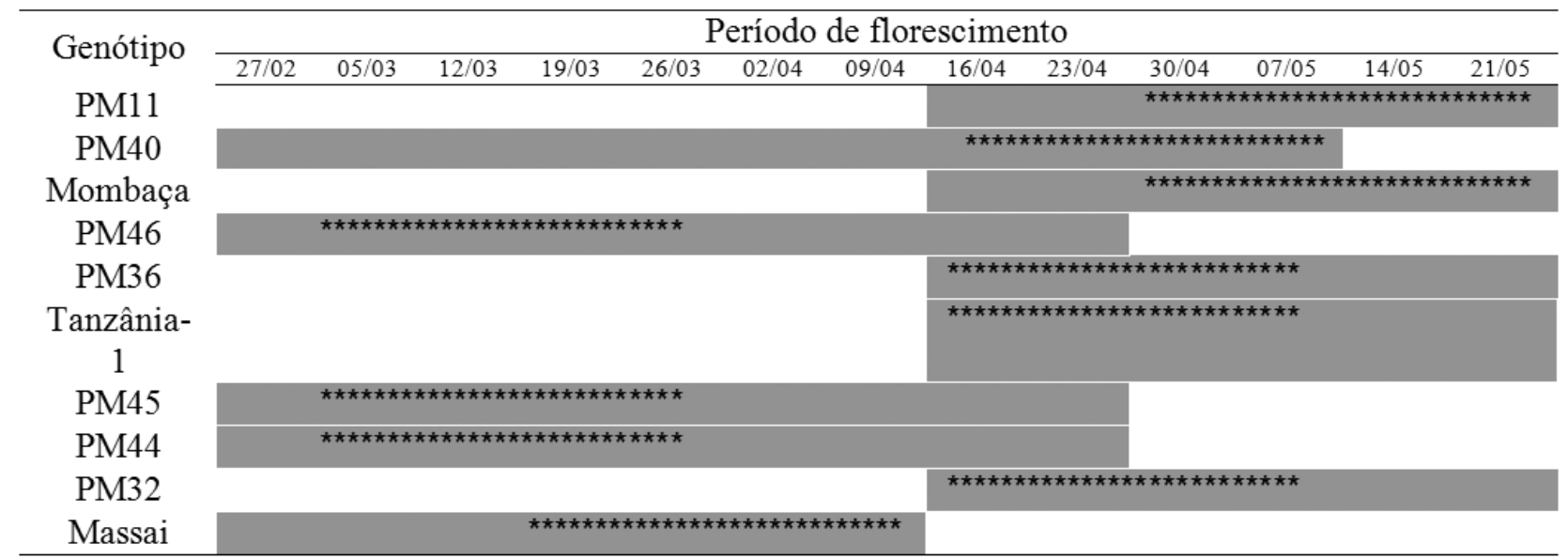

Período de florescimento

* Pico de doença

Figura 2. Período de florescimento e pico da cárie do sino de dez genótipos de Panicum maximum. Campo Grande-MS, 2012. 


\section{Experimento 2}

No segundo experimento, as maiores intensidades observadas da cárie do sino em plantas de $P$. maximum ocorreram em períodos distintos e variando segundo cada genótipo (Figura 3). Em todos os picos da doença neste experimento, as temperaturas e umidades relativas mínima e máxima ficaram entre $17^{\circ} \mathrm{C}$ e $27^{\circ} \mathrm{C}$ e $62 \%$ e $88 \%$, respectivamente. Estes resultados corroboram aqueles obtidos por Cruz Filho \& Chaves (12) para o mesmo patossistema (Figura 1).

As médias dos valores da severidade (AACPDS) e da incidência (AACPDI) da doença variaram de 1703,84 a 99,65 e de 2068,90 a 443,36 , respectivamente (Tabela 2) mostrando diferença quanto à resistência de genótipos de $P$. maximum em relação à cárie do sino.

Todos os genótipos testados neste experimento foram infectados pelo fungo (Tabela 2), ao contrário dos resultados encontrados por Jank et al. (18), onde alguns genótipos não apresentavam sintomas/sinais causados por T. ayresii. Resultados semelhantes foram encontrados por Muller et al. (26), que encontraram materiais genéticos de $P$. maximum livres do fungo, mostrando que há possibilidade de seleção de materiais candidatos a parentais para uso em programas de melhoramento da espécie, visando à resistência ao patógeno.

As médias de intensidade da cárie do sino em plantas de P. maximum foram muito maiores que as observadas no experimento 1 (Tabela 1). Tal fato pode ser explicado pelo espaçamento mais adensado neste experimento, o que pode ter facilitado a criação de microclima mais favorável à infecção e ao desenvolvimento do patógeno (3).

A cultivar Massai novamente apresentou baixa intensidade da doença, mostrando bom grau de resistência à cárie do sino em relação aos demais genótipos testados (Tabela 2). Analisando-se a severidade da doença (AACPDS), apresentada na mesma tabela, verifica-se que o genótipo PM11 e a cultivar Mombaça foram os mais suscetíveis ao patógeno, corroborando com os resultados de Anjos et al. (5) e Anjos et al. (6), onde a cultivar Mombaça apresentou alta severidade e a cultivar
Massai alta resistência à cárie do sino.

Fernandes et al. (16) classificaram a cultivar Massai no grupo de segunda maior incidência e entre os genótipos de maior severidade à cárie do sino. Tais discrepâncias de resultados indicam que as condições climáticas ambientais são importantes na expressão de resistência de campo no binômio $P$. maximum vs. T. ayresii, devendo ser realizadas pesquisas em condições controladas para elucidação desses resultados.

Em relação à avaliação da incidência, todos os materiais, com exceção da cultivar Massai, não diferiram estatisticamente entre si, apresentando médias altas deste índice (Tabela 2).

Resultados da avaliação de genótipos de Panicum maximum em relação à mancha foliar sob duas formas de manejo de corte

A análise de variância deste experimento mostrou que houve interação significativa entre genótipos x manejo de corte. Dessa forma, tais variáveis comportaram-se de forma dependente, sendo analisadas como tal (Tabela 3). As médias dos valores da área abaixo da curva de progresso das plantas sem corte (AACPDs) e a área abaixo da curva de progresso da doença das plantas com corte (AACPDc) variaram nos genótipos avaliados, de 35,21 a 1,40 e de 33,30 a 1,40, respectivamente (Tabela 3).

A temperatura e a umidade relativa variaram, durante a condução do experimento (fevereiro-abril $/ 2012$ ), entre $22^{\circ} \mathrm{C}$ e $27^{\circ} \mathrm{C}, 62 \%$ e $83 \%$, respectivamente (Figura 1). Tal intervalo de temperatura, conforme Costa et al. (10), é também ideal para a evolução da mancha foliar em milho, causada por B. maydis. Tais condições foram favoráveis à doença, visto que a severidade da mancha foliar na cultivar Tanzânia-1 (testemunha suscetível) foi bastante expressiva (Tabela 3).

Nos dois tipos de manejo adotados, os genótipos PM40 e Tanzânia-1 se comportaram como altamente suscetíveis à mancha foliar. Estes resultados corroboram aqueles obtidos por Machado et al. (22), quando verificaram alta suscetibilidade do genótipo Tanzânia-1 à doença.

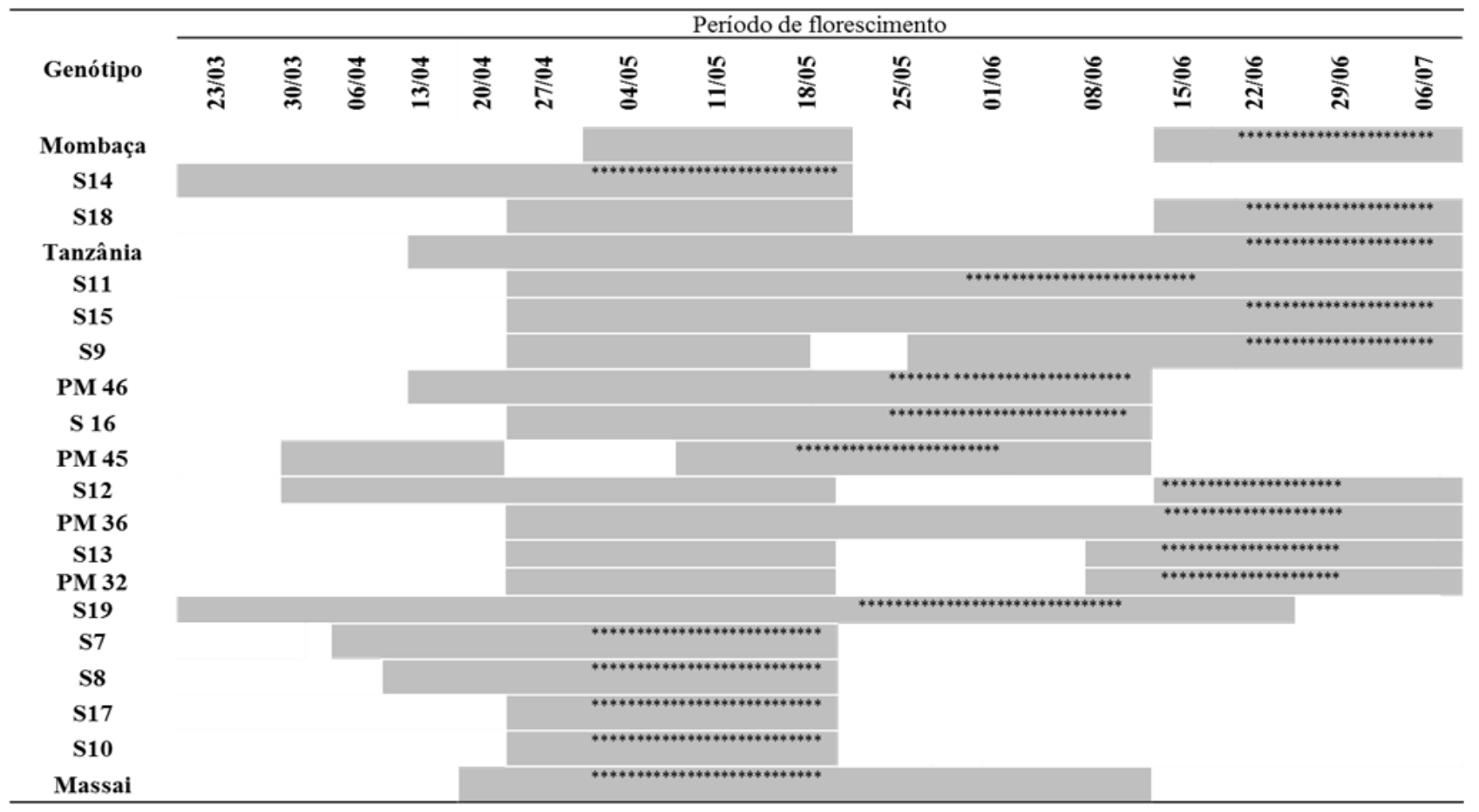

Figura 3. Período de florescimento e pico de cárie do sino de vinte genótipos de Panicum maximum. Campo Grande-MS, 2012.

Período de florescimento, * Pico da doença 
Tabela 2. Dados da intensidade de cárie do sino e parâmetros genéticos de Panicum maximum, expressos pelas áreas abaixo da curva de progresso da incidência (AACPDI) e da severidade (AACPDS). Campo Grande, MS, 2012

\begin{tabular}{ccc}
\hline Genótipo & AACPDS $^{\mathbf{1}}$ & AACPDI \\
\hline PM11 & $1703,84 \mathrm{a}^{*}$ & $2068,90 \mathrm{a}$ \\
Mombaça & $1531,84 \mathrm{a}$ & $2029,99 \mathrm{a}$ \\
PM40 & $1177,02 \mathrm{~b}$ & $2053,33 \mathrm{a}$ \\
Tanzânia-1 & $1079,64 \mathrm{~b}$ & $1858,89 \mathrm{a}$ \\
PM46 & $912,32 \mathrm{~b}$ & $1975,54 \mathrm{a}$ \\
PM32 & $902,13 \mathrm{~b}$ & $1800,55 \mathrm{a}$ \\
PM36 & $896,72 \mathrm{~b}$ & $1936,66 \mathrm{a}$ \\
PM44 & $830,66 \mathrm{~b}$ & $1819,98 \mathrm{a}$ \\
PM45 & $735,05 \mathrm{~b}$ & $1843,31 \mathrm{a}$ \\
Massai & $99,65 \mathrm{c}$ & $443,36 \mathrm{~b}$ \\
\hline Coeficiente de variação (\%) & 9,59 & 8,46 \\
\hline Herdabilidade- médias (\%) & 91,59 & 97,19 \\
Coeficiente de variação genético- médias (\%) & 18,27 & 28,74 \\
\hline
\end{tabular}

${ }^{1}$ Média de três repetições.

*Médias seguidas pelas mesmas letras nas colunas não diferem entre si pelo teste de Scott-Knott a 5\% de probabilidade.

Tabela 3. Severidade da mancha foliar em genótipos de Panicum maximum, expresso pelas áreas abaixo da curva de progresso da doença em plantas manejadas com corte de uniformização (AACPDc) e sem corte de uniformização (AACPDs). Campo Grande-MS.

\begin{tabular}{ccc}
\hline Genótipo & AACPDs & AACPDc \\
\hline Tanzânia-1 & $35,21 \mathrm{Aa}^{1}$ & $33,30 \mathrm{Ba}^{1}$ \\
PM40 & $36,13 \mathrm{Aa}$ & $32,58 \mathrm{Ba}$ \\
PM46 & $13,01 \mathrm{Ab}$ & $13,01 \mathrm{Ab}$ \\
Mombaça & $13,01 \mathrm{Ab}$ & $1,40 \mathrm{Bc}$ \\
PM36 & $13,01 \mathrm{Ab}$ & $1,40 \mathrm{Bc}$ \\
PM39 & $1,40 \mathrm{Ac}$ & $1,40 \mathrm{Ac}$ \\
Milênio & $1,40 \mathrm{Ac}$ & $1,40 \mathrm{Ac}$ \\
PM30 & $1,40 \mathrm{Ac}$ & $1,40 \mathrm{Ac}$ \\
PM11 & $1,40 \mathrm{Ac}$ & $1,40 \mathrm{Ac}$ \\
PM32 & $1,40 \mathrm{Ac}$ & $1,40 \mathrm{Ac}$ \\
\hline Médias & $11,74 \mathrm{~A}$ & $8,87 \mathrm{~B}$ \\
\hline Coeficiente de variação $(\%)$ & 9,45 & 9,93 \\
\hline
\end{tabular}

*Médias seguidas pelas mesmas letras maiúsculas nas linhas e minúsculas nas colunas não diferem entre si pelo teste de Tukey a 5\% de probabilidade.

Resultados semelhantes foram encontrados por Amorim et al. (2), quando avaliaram a resistência de genótipos de $P$. maximum em relação a isolados de B. maydis, e relataram que o genótipo Tanzânia-1 foi mais suscetível que o Mombaça e PM32.

No sistema de manejo das plantas com corte foram observadas menores intensidades da doença (Tabela 3 ). Este fato pode ser explicado devido à redução de inóculo na área via remoção de sítios e microclima desfavorável ao patógeno, elevando a circulação de ar. Charchar et al. (8) verificaram que a cultivar Mombaça apresentou resistência à mancha foliar, diferindo desta pesquisa, situação em que apresentou comportamento intermediário em relação ao patógeno da mancha foliar.

Com o presente trabalho foi possível verificar que, dentre os genótipos de Panicum maximum estudados, existe variabilidade para resposta de resistência à cárie do sino e à mancha foliar.

As condições ambientais de temperatura e umidade relativa do ar favoráveis à cárie do sino foram $16^{\circ} \mathrm{C}$ a $27^{\circ} \mathrm{C}$ e $62 \%$ a $88 \%$ e à mancha foliar foram $22^{\circ} \mathrm{C}$ a $27^{\circ} \mathrm{C}$ e $62 \%$ a $83 \%$.

A resistência à cárie do sino mostrou ser caráter altamente herdável. Os genótipos PM40 e Tanzânia-1 podem ser usados como testemunha suscetível em relação à cárie do sino e à mancha foliar, respectivamente.

O manejo de P. maximum com corte de uniformização proporcionou melhor sanidade das plantas podendo constituir mais uma ação para o manejo cultural da doença.

\section{AGRADECIMENTOS}

Embrapa Gado de Corte, Universidade Estadual de Mato Grosso do Sul, Capes, CNPq, Fundect, Unipasto e Fundapam.

\section{REFERÊNCIAS BIBLIOGRÁFICAS}

1. Agrios, G.N. Plant pathology. 4. ed. New York e USA: Academic Press, 1997. 635p.

2. Amorim, T.R.; Silva, M.J.; Fernandes, C.D.; Jank, L.; Meireles, K.G.X. Avaliação de genótipos de Panicum maximum quanto à resistência a Bipolaris maydis. In: International Symposium on Forage Breeding, 3., 2011, Bonito. Anais. Bonito: Embrapa Gado de Corte, 2011. p.254-257.

3. Andres, A.; Magalhães Júnior, A.M.; Nunes, C.D.; Franco, D.F.; Theisem, G.; Madail, J.C.M.; Petrini, J.A.; Reis, J.C.; Martins, J.F.S.; Mattos, M.L.T.; Melo, M.; Fagundes, P.R.R.; Scivittaro, W.B. Cultivo de arroz irrigado orgânico no Rio Grande do Sul. Pelotas: Embrapa Clima Temperado, 2009. 160p. (Sistema de Produção, 17).

4. Anjos, J.R.N.; Charchar, M.J.A.; Anjos, S.S.N. Bipolaris maydis causando mancha foliar em Paspalum atratum cv. Pojuca no Brasil. Fitopatologia Brasileira, Brasília, v.29, n.6, p.656-658, 2004.

5. Anjos, J.R.N.; Charchar, M.J.A.; Fernandes, F.D.; Silva, M.S.; Silva W.A.M. Avaliação da severidade do carvão (Tilletia ayressi) em Panicum maximum no Cerrado. Fitopatologia Brasileira, Brasília, v.31, p.242, 2006. Suplemento.

6. Anjos, J.R.N.; Charchar, M.J.A.; Vieira, E.A.; Fernandes, F.D.; Silva, M.S.; Ramos, A.K.B. Avaliação da resistência genética de genótipos de Panicum maximum ao fungo Tilletia ayresii. Planaltina: Embrapa Cerrados, 2009. 13p. (Boletim técnico, 254).

7. Braz, T.G.S.; Jank, J.; Fonseca, D.M.; Resende, M.D.V.; Simeão, R.M. Parâmetros genéticos de caracteres agronômicos em híbridos de Panicum maximum Jacq. In: International Symposium on Forage Breeding, 3., 2011, Bonito. Anais. Bonito: Embrapa Gado de Corte, 2011. p.250-253.

8. Charchar, M.J.A.; Vieira, E.A.; Anjos, J.R.N.; Fernandes, D.F.; Silva, M.S.; Michalski, M.V. Severidade de manchas foliares em genótipos de Panicum maximum no cerrado do Brasil Central. Planaltina-DF: Embrapa Cerrados, 2006. 1p.

9. Charchar, M.J.A.; Anjos, J.R.N.; Silva, M.S.; Silva, W.A.M. Mancha foliar em capim-elefante no Cerrado do Brasil Central causada por Bipolaris maydis. Pesquisa Agropecuária Brasileira, Brasília, v.43, n.11, p.1637-1639, 2008.

10. Costa, R.V.; Casela, C.V.; Cota, L.V. Cultivo do milho. 5. ed. Sete Lagoas: Embrapa Milho e Sorgo, 2009. 53p. (Sistema de Produção, 2).

11. Cruz, C.D. Programa genes: análise multivariada e simulação. Viçosa: UFV, 2006. 175p.

12. Cruz Filho, J.; Chaves, G.M. Doenças de plantas: carvões e cáries. 2.ed. Viçosa: UFV, 1993. 12p

13. Da Silva, S.C., Nascimento Júnior, D. Ecofisiologia de plantas forrageiras In: Pereira, O.G.; Obeid, J.A.; Nascimento Jr., D.; Fonseca, D.M. (Eds.). Simpósio sobre manejo estratégico da pastagem, 3., Viçosa, 2006. Anais. Viçosa: UFV, 2006. p.1-42.

14. Delgado, A.; Machado, H.; Paz, G. Evaluación de la resistencia a hongos de las hespiculas em uma colleción introducida de $P$. maximum Jacq. Pastos y Forrajes, Matanzar, v.13, p.59-65, 1990.

15. Fernandes, C.D.; Chermouth, K.S.; Jank, L.; Mallmann, G.; Fernandes, E.T.; Queiróz, C.A.; Carvalho, C.; Quetez, F.A.; Silva, M.J.; Batista, M.V. Reação de híbridos de Panicum maximum à mancha das folhas em condições de infecção natural. In: International Symposium on Forage Breeding, 3., 2011, Bonito. Anais. Bonito: Embrapa Gado de Corte, 2011a. p.59-61.

16. Fernandes, C.D.; Fernandes, E.T.; Mallmann, G.; Jank, L.; Verzignassi, J.R.; Batista, M.B.; Chermouth, K.S.; Queiróz, C.A.; Silva, M.J.; Carvalho, C.; Quetez, F.A. Intensidade de cárie do sino em genótipos de Panicum maximum. In: International Symposium on Forage Breeding, 3., 2011, Bonito. Anais. Bonito: Embrapa Gado de Corte, 2011b. p.56-58. 
17. Fonseca, D.M.; Santos, M.E.R.; Martuscello, J.A. Importância das forrageiras no sistema de produção. In: Fonseca, D.M.; Martuscello, J.A. Plantas forrageiras. Viçosa: Universidade Federal de Viçosa, 2010. v.1, p.13-29.

18. Jank, L.; Verzignassi, J.R.; Urben, A.F.; Fernandes, C.D.; Fernandes, J.M.; Valle, C.B. Ocorrência de Tilletia ayresii em genótipos de Panicum maximum em Campo Grande-MS. Fitopatologia Brasileira, Brasília, v.26, p.422-423, 2001. Suplemento.

19. Kimati, H.; Bergamin Filho, A. In: Bergamin Filho, A.; Kimati, H.; Amorim, L. Manual de fitopatologia: princípios e conceitos. 3. ed. São Paulo: Agronômica Ceres, 1995. p.692-728.

20. Lazia, B. Produção de forrageiras, 2012. Portal Agropecuário. Disponível em: $<$ http://www.portalagropecuario.com.br/bovinos/pastagens-e-alimentacao/ producao-de-forrageiras/> . Acesso em: 02 fev. 2013.

21. Lima, M.D.; Jank, L.; Pereira, E.S. Incidência do fungo Tilletia ayresii em híbridos de Panicum maximum. In: Jornada Ciênctifica, 8., 2012, Campo Grande. Anais. Campo Grande: Embrapa Gado de Corte, 2012. p.102-103.

22. Machado, L.A.Z.; Jank, L.; Roese, A.D. Avaliação de genótipos de Panicum maximum para produção de forragem em sucessão a soja. In: International Symposium on Forage Breeding, 2., 2009, Campo Grande. Anais. Campo Grande: Embrapa Gado de Corte, 2009. 1 CD-ROM.

23. Marques, A.C.B. Variabilidade genética molecular em plantas apomíticas e sexuais do banco de germoplasma de Panicum maximum Jacq. In: International Symposium on Forage Breeding, 3., 2011, Bonito. Anais. Bonito:
Embrapa Gado de Corte, 2011. p.38-41.

24. Martinez, A.S. Avaliação do dano provocado por Bipolaris maydis em Panicum maximum cv. Tanzânia-1. 2006. 33p. Dissertação (Mestrado em Agronomia) - Universidade Estadual do Oeste do Paraná, Marechal Candido Rondon.

25. Martinez, A.S.; Franzener, G.; Stangarlin, J.R. Dano causado por Bipolaris maydis em Panicum maximum cv. Tanzânia-1. Ciências Agrárias, Londrina, v.31, n.4, p.863-870, 2010.

26. Muller, J.A.I.; Moura, S.S.; Fernandes, C.D.; Jank, L.; Verzignassi, J.R.; Mallmann, G.; Queiróz, C.A.; Batista, M.V.; Santos, E.C.M.; Falco, T.E.; Garcia, A.A.; Quetez, F.A. Intensidade de cárie do sino em acessos de Panicum maximum Jacq. In: Jornada Científica, 8., 2012, Campo Grande. Anais. Campo Grande: Embrapa Gado de Corte, 2012. p.58-59.

27. Nunes, C.D.M.; Brancão, N. Carvão do arroz: epidemiologia, ocorrência e controle. Pelotas: Embrapa Clima Temperado, 2006. 7p. (Comunicado Técnico, 146).

28. Shaner, G.; Finney, R.E. The effect of nitrogen fertilization on the expression of slow-mildewing resistance in knox wheat. Phytopathology, Saint Paul, v.70, n.8, p.1183-1186, 1977.

29. Unipasto. Informações técnicas de produção e comercialização de sementes forrageiras, 2012 Disponível em: <http://www.unipasto.com.br/ publicacoes.php>. Acesso em: 18 fev. 2013.

30. Verzignassi, J.R.; Fernandes, C.D. Doenças em forrageiras. Campo Grande: Embrapa Gado de Corte, 2001. 3p. (Circular Técnica, 50). 